\title{
Changes in skeletal muscle thickness and echogenicity and plasma creatinine concentration as indicators of protein and intramuscular fat mobilization in periparturient dairy cows
}

\author{
A. A. Megahed, ${ }^{1,2,3}$ M. W. H. Hiew, ${ }^{1,4}$ D. Ragland, ${ }^{1}$ and P. D. Constable ${ }^{2 *}$ \\ ${ }^{1}$ Department of Veterinary Clinical Sciences, College of Veterinary Medicine, Purdue University, West Lafayette, IN 47905 \\ ${ }^{2}$ Department of Veterinary Clinical Medicine, College of Veterinary Medicine, University of Illinois, Urbana 61802 \\ ${ }^{3}$ Department of Animal Medicine, Internal Medicine, Faculty of Veterinary Medicine, Benha University, Moshtohor-Toukh, Kalyobiya, 13736, Egypt \\ ${ }^{4}$ Department of Veterinary Clinical Studies, Faculty of Veterinary Medicine, Universiti Putra, Selangor, 43400, Malaysia
}

\section{ABSTRACT}

High-producing dairy cows experience a state of negative energy balance in the periparturient period that is partially addressed by increasing the rate of fat and protein mobilization. Previous studies have focused on the rate of fat mobilization, and consequently the rate of protein mobilization has not been well characterized. The objective of this study was therefore to determine the change in indicators of muscle mass during early lactation using ultrasonographic measurement of muscle thickness and changes in plasma creatinine concentration. The maximum thickness of the gluteus medius and longissimus dorsi muscles of 106 Holstein cows (34 primiparous, 72 multiparous) was determined ultrasonographically on $\mathrm{d}-3,0,3,7,14,21$, and 28 relative to the day of parturition. Plasma creatinine concentration was measured periodically during the same period. Mixed models analysis and PassingBablok regression were used to analyze the data. Gluteus medius thickness, longissimus dorsi loin thickness (LDLT), and longissimus dorsi thoracic thickness (LDTT) were decreased at $28 \mathrm{~d}$ postpartum compared with d 3 antepartum. Plasma creatinine concentration was weakly associated with gluteus medius thickness, LDLT, and LDTT (Spearman's rho $=0.31,0.39$, and 0.32 , respectively). Plasma creatinine concentration in primiparous and multiparous cows at $28 \mathrm{~d}$ postpartum decreased by 0.24 and $0.30 \mathrm{mg} / \mathrm{dL}$, respectively, compared with values $3 \mathrm{~d}$ antepartum. We concluded that ultrasonographic measurement of LDLT and LDTT and change in plasma creatinine concentration may provide practical methods for monitoring the rate of protein mobilization in periparturient dairy cows. Ultrasono-

Received May 14, 2018.

Accepted January 21, 2019.

*Corresponding author: constabl@illinois.edu graphic examination of LDLT and LDTT therefore complements ultrasonographic measurement of backfat thickness and may be useful in the evaluation of energy reserve mobilization in periparturient dairy cows.

Key words: muscle mobilization, negative energy balance, intramuscular fat

\section{INTRODUCTION}

A state of negative energy and protein balance commonly occurs during the periparturient period in dairy cows (Drackley, 1999; Herdt, 2000). The energy balance has been estimated at $-5.8 \mathrm{Mcal} / \mathrm{d}$ close to parturition and up to $-20 \mathrm{Mcal} / \mathrm{d}$ during the first month of lactation (Grummer et al., 2004). The marked energy deficit in periparturient dairy cows cannot be fully addressed by increasing feed intake, resulting in mobilization of adipose and muscle tissue (Tamminga et al., 1997; van der Drift et al., 2012). The amount of adipose tissue mobilized during early lactation varies markedly from cow to cow, ranging from 8 to $57 \mathrm{~kg}$ of body fat (Komaragiri et al., 1998). For comparison, approximately 20 $\mathrm{kg}$ of skeletal muscle is mobilized during early lactation (Komaragiri et al., 1998). Fat mobilization seems to start after parturition and continues up to 8 wk after parturition (Bruckmaier et al., 1998a; van der Drift et al., 2012). In contrast, skeletal muscle mobilization appears to start before parturition and continues up to 5 wk after parturition, with the rate of mobilization peaking during the first 2 wk of lactation (Reid et al., 1980; Sloniewski et al., 2004; van der Drift et al., 2012; Schäff et al., 2013).

Ultrasonography has been extensively used in the beef industry for more than $40 \mathrm{yr}$ to predict carcass composition (Gillis et al., 1973) and has been increasingly used over the last $20 \mathrm{yr}$ to evaluate the rate and extent of fat mobilization in periparturient dairy cows via measurement of subcutaneous backfat thickness (BFT; Domecq et al., 1995; Schröder and Staufenbiel, 
2006). A small number of studies have used ultrasonography to monitor the rate and extent of muscle mobilization in periparturient dairy cows (Bruckmaier et al., 1998a; Kokkonen et al., 2005; van der Drift et al., 2012). Ultrasonographic measurement of gluteus medius thickness (GMT) and the thickness of the longissimus dorsi at the level of loin area (LDLT) and thoracic area (LDTT) has been used to monitor the accretion of muscle and fat in growing beef bulls and steers (Bruckmaier et al., 1998b; Realini et al., 2001) and periparturient dairy cows (Moorby et al., 2002; Kokkonen et al., 2005; van der Drift et al., 2012). To our knowledge, only a handful of studies have investigated the effect of parity on backfat and skeletal muscle mobilization in periparturient Holstein-Friesian cows (Moorby et al., 2002; Wathes et al., 2007; van der Drift et al., 2012; Jaurena and Moorby, 2017). Two ultrasonographic studies examining relatively small numbers of periparturient Holstein-Friesian cows found no effect of parity on backfat and skeletal muscle mobilization (Moorby et al., 2002; van der Drift et al., 2012). We hypothesized that the periparturient mobilization of backfat and skeletal muscle would be greater in primiparous than multiparous cows because primiparous cows are still growing. Moreover, peak milk production is lower in primiparous cows and occurs later in lactation than in mature cows, potentially affecting the homeostatic response to net negative energy balance in early lactation.

A concern with using ultrasonographically determined changes in muscle thickness to quantify the rate of skeletal muscle mobilization is the presence of intramuscular fat (IMF) that is located among and between skeletal muscle fibers. It is possible that the periparturient decrease in muscle thickness (Bruckmaier et al., 1998a; van der Drift et al., 2012) may reflect a decrease in IMF rather than a decrease in skeletal muscle tissue. Ultrasonography provides a valuable tool to quantify the IMF content in beef cows (Aass et al., 2009; Silva et al., 2010) and humans (Pillen et al., 2009) by quantifying muscle echogenicity through grayscale analysis (Silva et al., 2010). Our second hypothesis was that periparturient decreases in muscle thickness reflect mobilization of both skeletal muscle and IMF.

Creatinine is formed at a constant rate in mammals from the spontaneous, irreversible, nonenzymatic conversion of creatine in skeletal muscle (Wyss and Kaddurah-Daouk, 2000; Braun et al., 2003). Muscle creatinine is the main source of plasma and urinary creatinine, and any change in skeletal muscle mass in healthy euhydrated animals with normal renal function results in a change in plasma creatinine concentration; Wyss and Kaddurah-Daouk, 2000). Parallel decreases in plasma creatinine concentration and ultrasonograph- ically determined muscle mass have been identified in periparturient multiparous dairy cows (Bruckmaier et al., 1998a; Kokkonen et al., 2005). Surprisingly, we could not identify any research studies that statistically examined whether plasma creatinine concentration was correlated with ultrasonographically determined muscle thickness in periparturient dairy cows. Therefore, our third hypothesis was that monitoring the change in plasma creatinine concentration over the periparturient period provides a clinically useful indicator of the rate of skeletal muscle mobilization. Based on these hypotheses, the first objective of this study was to characterize and compare the change in muscle mass during the periparturient period in primiparous and multiparous cows using ultrasonography and change in plasma creatinine concentration. A second objective was to determine the association between BCS and indices of muscle mass (plasma creatinine concentration, GMT, LDLT, and LDTT) and indices of fat content (BFT, IMF) in periparturient dairy cows using linear and multivariate regression analysis. We anticipated that the results of this study would indicate whether monitoring changes in muscle thickness or plasma creatinine concentration was useful for evaluating the rate of energy reserve mobilization in periparturient dairy cows.

\section{MATERIALS AND METHODS}

All methods were evaluated and approved by the Purdue Animal Care and Use Committee under protocol number 1201000598. The study reported here was part of a larger study investigating the prediction of parturition and dystocia along with energy and calcium homeostasis in the periparturient period in HolsteinFriesian cows. Additional results have been published elsewhere (Megahed et al., 2015, 2018a,b; Hiew et al., 2016).

\section{Animals, Housing, and Feeding}

An observational longitudinal cohort study was conducted using a convenience sample of 106 late-gestation nonlactating Holstein-Friesian cows (34 primiparous, 72 multiparous) from the Purdue University Dairy Research and Education Center over a 10-mo period between May 29, 2012, and March 29, 2013. A total of 240 animals calved during the course of the study; 134 of these animals were not enrolled in the study due to workload constraints. Cows were housed outdoors in a dry lot and fed an acidogenic TMR [Table 1; DCAD $=-10 \mathrm{mEq} / 100 \mathrm{~g}$ of DM, where DCAD $=\left(\left[\mathrm{Na}^{+}\right]+\right.$ $\left.\left[\mathrm{K}^{+}\right]\right)-\left(\left[\mathrm{Cl}^{-}\right]+\left[\mathrm{SO}_{4}{ }^{2-}\right]\right)$; Megahed et al., 2018a] based on formulations recommended by NRC (2001) for closeup cows. Primiparous and multiparous cows were fed 
acidogenic close-up rations starting 6 and 3 wk before parturition, respectively. The ration was offered once daily between 0800 and $0930 \mathrm{~h}$ and consisted predominantly of orchard grass hay, alfalfa haylage, and corn silage. Water was available ad libitum.

Enrolled cows were moved from the outdoor dry lot to individual box stalls $\left(9.3 \mathrm{~m}^{2}\right)$ located indoors at $4 \mathrm{~d}$ before the estimated parturition date based on breeding records and pregnancy diagnosis at approximately 40

Table 1. Ingredients and chemical composition of the close-up and lactation rations fed to 106 periparturient Holstein cattle during the study

\begin{tabular}{|c|c|c|}
\hline Item & $\begin{array}{l}\text { Close-up } \\
\text { ration }\end{array}$ & $\begin{array}{l}\text { Lactation } \\
\text { ration }\end{array}$ \\
\hline \multicolumn{3}{|l|}{ Ingredient $(\%$ of $\mathrm{DM})$} \\
\hline Corn silage & 40.6 & 34.6 \\
\hline Prefresh grain & 28.7 & - \\
\hline Orchard grass hay & 10.3 & 3.3 \\
\hline Cottonseed hulls & 7.4 & - \\
\hline Alfalfa silage & 6.9 & 17 \\
\hline High-moisture shelled corn $27.6 \%$ & 4.3 & 19.1 \\
\hline Perdue LysAAmet Blend ${ }^{1}$ & 1.8 & 1.7 \\
\hline Soybean meal & - & 9.4 \\
\hline Purdue dairy supplement ${ }^{2}$ & - & 7.1 \\
\hline Soybean hulls pellet & - & 4.3 \\
\hline Double S molasses $42 \%^{3}$ & - & 2.6 \\
\hline Wheat straw & & 0.9 \\
\hline \multicolumn{3}{|l|}{ Chemical analysis } \\
\hline DM (\% as fed) & 45.53 & 52.04 \\
\hline $\mathrm{NDF}(\%$ of DM) & 36.12 & 29.95 \\
\hline $\mathrm{ADF}(\%$ of $\mathrm{DM})$ & 23.65 & 20.83 \\
\hline Forage NDF adjusted (\%) & 26.24 & 24.10 \\
\hline NFC $(\%)$ & 36.00 & 43.25 \\
\hline Sugar $(\%)$ & 2.82 & 4.18 \\
\hline Starch $(\%)$ & 24.76 & 28.02 \\
\hline Forage $(\%)$ & 65.11 & 55.63 \\
\hline $\mathrm{CP}(\%)$ & 15.48 & 16.05 \\
\hline Soluble protein (\%) & 7.1 & 6.61 \\
\hline $\mathrm{RDP}(\%)$ & 7.22 & 10.44 \\
\hline $\mathrm{Ca}(\%)$ & 1.03 & 0.90 \\
\hline $\mathrm{P}(\%)$ & 0.31 & 0.38 \\
\hline $\mathrm{Mg}(\%)$ & 0.43 & 0.36 \\
\hline $\mathrm{K}(\%)$ & 1.2 & 1.30 \\
\hline $\mathrm{Na}(\%)$ & 0.2 & 0.36 \\
\hline $\mathrm{Cl}(\%)$ & 1.14 & 0.52 \\
\hline $\mathrm{S}(\%)$ & 0.39 & 0.22 \\
\hline $\operatorname{Mn}(\mathrm{mg} / \mathrm{kg})$ & 708.4 & 764.4 \\
\hline $\mathrm{Cu}(\mathrm{mg} / \mathrm{kg})$ & 183.7 & 198.2 \\
\hline $\mathrm{Zn}(\mathrm{mg} / \mathrm{kg})$ & 835.2 & 901.3 \\
\hline $\mathrm{I}(\mathrm{mg} / \mathrm{kg})$ & 6.6 & 7.1 \\
\hline $\mathrm{Co}(\mathrm{mg} / \mathrm{kg})$ & 23.8 & 25.7 \\
\hline $\mathrm{Se}(\mathrm{mg} / \mathrm{kg})$ & 1.11 & 1.0 \\
\hline Vitamin A (kIU/kg) & 5.6 & 6.3 \\
\hline Vitamin $\mathrm{D}_{3}(\mathrm{kIU} / \mathrm{kg})$ & 1.2 & 1.3 \\
\hline Vitamin E $(\mathrm{IU} / \mathrm{kg})$ & 133.0 & 148.1 \\
\hline Monensin $^{4}$ (mg/kg) & 30.6 & 33.0 \\
\hline DCAD $(\mathrm{mEq} / 100 \mathrm{~g})$ & -17.5 & +20.4 \\
\hline
\end{tabular}

${ }^{1}$ Perdue AgSolution LLC (Salisbury, MD).

${ }^{2}$ Purdue University Dairy Research and Education Center (West Lafayette, IN).

${ }^{3}$ Double S Liquid Feed Inc. (Danville, IL).

${ }^{4}$ Elanco Animal Health (Indianapolis, IN). d after insemination. All animals were deemed healthy based on daily routine physical examinations in the box stalls. Periparturient diseases were diagnosed using standardized definitions and recorded by trained farm personnel. The time of calving was recorded to the nearest hour by farm personnel. After calving, all cows were kept in the same individual boxstalls or tiestalls for $3 \mathrm{~d}$ or until they recovered from any postpartum health issues before being moved to a freestall. Cows were switched to a lactating cow TMR after calving based on formulations recommended by NRC (2001) for fresh cows (Table 1). This ration was based on corn silage, alfalfa haylage, and high-moisture corn. The ration was formulated using Agricultural Modeling and Training Systems Cattle Professional software (version 3.4.7.1, AMTS LLC, Groton, NY). Weekly samples of TMR were frozen at $-20^{\circ}$ and submitted for analysis at a commercial laboratory (Perdue Agribusiness Inc., Salisbury, MD). Enrolled cows were milked twice daily after parturition between 0515 and $0830 \mathrm{~h}$ and between 1600 and $1900 \mathrm{~h}$ in a milking parlor. Daily milk production was recorded using the dairy's automatic recording software (PCDART; Dairy Records Management Systems, Raleigh, NC), and 305-d mature-equivalent milk, fat, and protein yields were calculated and recorded after the lactation was completed. Milk production indices therefore represented actual and not projected values as the majority of animals completed their lactation.

\section{Experimental Methods}

Blood samples were obtained daily at approximately $0900 \mathrm{~h}$ before the morning feeding from the coccygeal vein or artery into 10-mL lithium heparin blood collection tubes (BD Diagnostics, Franklin Lakes, NJ). Blood samples were obtained on $\mathrm{d}-3,-2,-1,0,1,2$, and 3 and then at approximately weekly intervals from $d$ 4 to 35 of lactation, with the day of calving being $\mathrm{d}$ 0 . Heparinized blood samples were transported after collection to a climate-controlled laboratory area that was adjacent to the animal housing area. Packed cell volume was measured in triplicate using plain capillary tubes after centrifugation at room temperature for 5 min at $14,800 \times g$, and the mean value was recorded. The heparinized blood sample was then centrifuged at room temperature for $5 \mathrm{~min}$ at $1,300 \times g$ within $30 \mathrm{~min}$ of collection. Plasma was harvested and total protein concentration was measured in triplicate using a handheld analog refractometer (Master-SUR/N $\alpha$, Atago Co. Ltd., Fooma, Japan) and the mean value was recorded. The remaining plasma was transferred into polypropylene vials within $1 \mathrm{~h}$ of centrifugation and stored at $-20^{\circ} \mathrm{C}$. 
Thoracic circumference (heart girth) was measured in a vertical plane immediately caudal to the scapula once in the $3 \mathrm{~d}$ before parturition. Body weight was calculated from thoracic circumference (heart girth) using a quadratic equation developed from Holstein-Friesian heifers 1 to $821 \mathrm{~d}$ of age (Heinrichs et al., 1992). Body condition score (on a 1-to-5 scale) was estimated on d -3 , and 3 and then at approximately weekly intervals from d 4 to 35 of lactation on the same day as blood sampling using an established scoring system (Ferguson et al., 1994; Health, 1996).

Backfat thickness, GMT, LDLT, and LDTT were measured ultrasonographically on the same day that BCS was estimated. Backfat thickness and GMT were measured at the sacral area adjacent to the first coccygeal vertebra (Figure 1A), as described for dairy cows (Bruckmaier et al., 1998a,b; Schröder and Staufenbiel, 2006). Longissimus dorsi muscle thickness was measured at 2 points: at the level of the 5th lumbar vertebrae (LDLT; Figure 1B) and at the level between the 12th and 13th ribs (LDTT; Figure 1C), as described for dairy and beef cows (Bruckmaier et al., 1998a,b; Moorby et al., 2002). Briefly, hair was clipped at the measurement points and a portable ultrasonographic unit (Exago 90-1119 ECM ultrasound; Universal Solutions Inc., Bedford Hills, NY) with a $5-\mathrm{MHz}$ linear transducer was applied using B mode, power at $100 \%$, gain at 0 , and $80-\mathrm{mm}$ depth. The animal was placed in a relaxed standing position with the weight equally distributed on the left and right legs, and $70 \%$ alcohol and coupling gel were applied to facilitate transducer contact. The transducer was positioned lightly and vertically to the interface of fat and muscle to avoid compression of fat and muscle and perpendicular to the vertebral column (Brethour, 1992; Sloniewski et al., 2004; van der Drift et al., 2012). The longissimus dorsi muscle was measured in the transverse plane to facilitate comparison of results with other studies in dairy cows (Bruckmaier et al., 1998a; Moorby et al., 2002; Kokkonen et al., 2005). Suitable ultrasonographic images (RGB, $640 \times 480$ pixels, 8 -bit, providing an apparent spatial resolution of $125 \mu \mathrm{m} /$ pixel) were stored for subsequent offline analysis.

\section{Measurement of BFT and Skeletal Muscle Thickness}

The thickness of the backfat, gluteus medius muscle, and longissimus dorsi muscle was measured perpendicular to the skin at the thickest section (Schröder and Staufenbiel, 2006) using the straight freehand line tool of ImageJ software (National Institutes of Health, Bethesda, MD). Superficial fascia and profound fascia were used as landmarks for measuring BFT, where the straight freehand line extended from the midpoint of the superficial fascia to the midpoint of the profound fascia. Muscle depth was measured instead of muscle area to provide a similar method to that for measuring $\mathrm{BFT}$ and because the area of the gluteus medius muscle could not be easily and rapidly measured. For the GMT, LDLT, and LDTT measurements, the straight freehand line extended between the 2 connective tissue layers (fascia) ensheathing the muscle bundles to measure only muscle tissue at the thickest section. The investigator measuring fat and muscle thickness did not have access to BCS information, and all image analysis was done by one operator (AM) to eliminate the potential for subjective operator-to-operator differences.

\section{Measurement of Muscle Echogenicity}

Hyperechoic flecks (speckles) are evident when skeletal muscle is examined ultrasonographically in the transverse plane (Pillen, 2010). Hyperechoic flecks indicate increased echogenicity due to reflections of perimysial connective tissue and IMF (Pillen, 2010) and therefore provide information regarding changes in IMF. Echogenicity was quantified using grayscale analysis. Blurred ultrasonographic images and images with echoes $(n=14)$ were not analyzed because image quality was not suitable for analysis.

Grayscale analysis involved converting the 8-bit RGB image to an 8-bit grayscale image, with the mean echogenicity of a region of interest (ROI) being expressed as a value between 0 (pure black) and 255 (pure white). The freehand selection tool in the Image J software program (version 1.50i, National Institutes of Health) was used to identify an ROI that included as much of the muscle as possible, avoiding areas with artifacts, bone, or surrounding fascia (epimysium). This ROI method minimizes the effect of differences in depth on the echogenicity value compared with application of a rectangular box, as mean tissue echogenicity decreases with increases in depth (Thijssen et al., 2008; Starke et al., 2010). Echogenicity of the ROI was quantified using the standard histogram function in the ImageJ software program. A decrease in the mean grayscale value for echogenicity indicated mobilization of IMF or connective tissue (Aass et al., 2009; Young et al., 2015) or an increase in subcutaneous fat depth and muscle depth (Thijssen et al., 2008; Starke et al., 2010).

\section{Plasma Biochemical Analysis}

Plasma samples were thawed at room temperature, and selected indices of protein metabolism (creatinine, urea nitrogen, and albumin) were determined spec- 

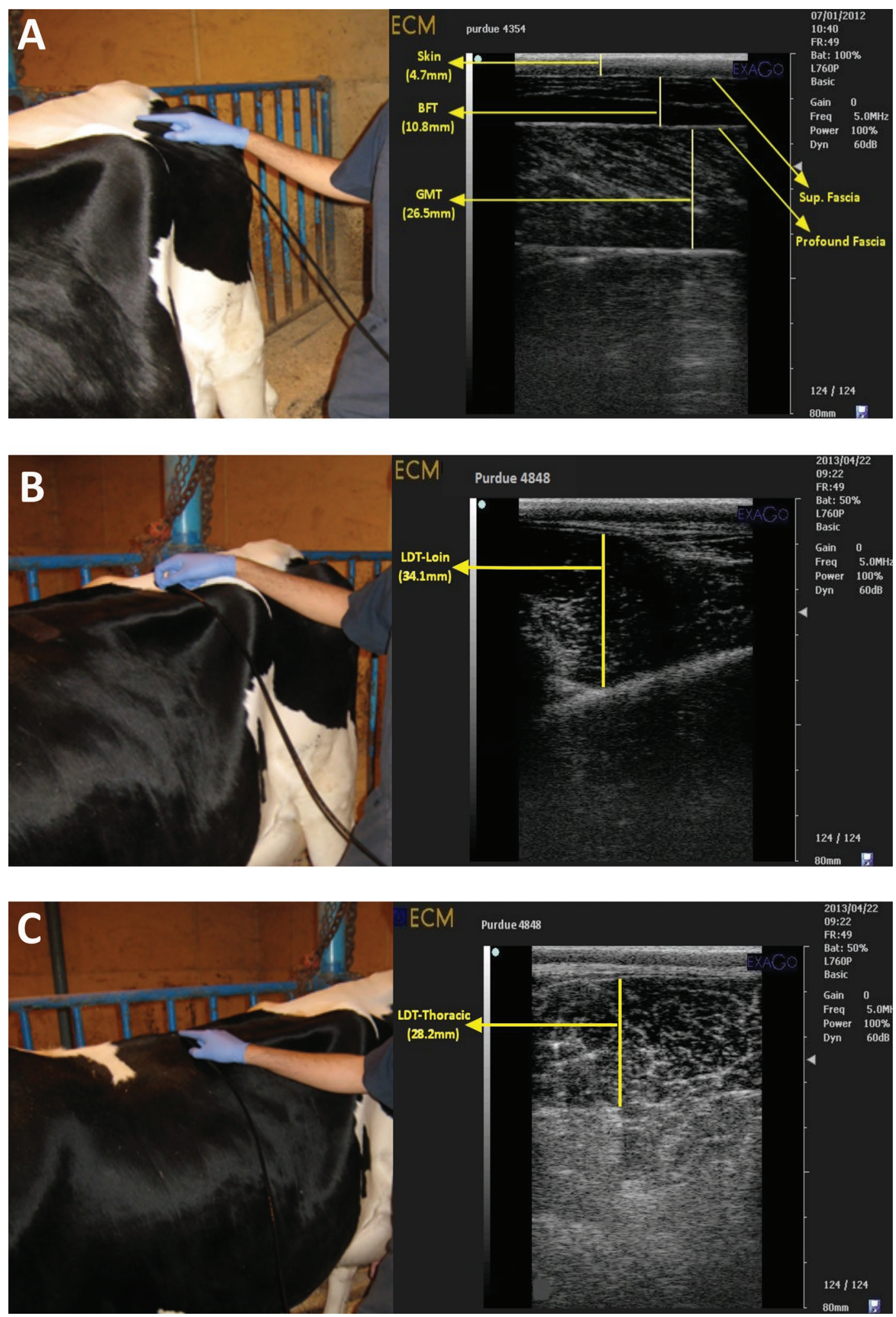

Figure 1. Measurement of (A) backfat thickness (BFT) and gluteus medius muscle thickness (GMT) at the sacral area adjacent to the first coccygeal vertebra, (B) longissimus dorsi muscle thickness (LDT) at the level of the 5th lumber vertebrae, and (C) LDT between the 12th and 13th ribs. Ultrasonographic images were obtained using a 5-MHz transducer, and thickness measurements were obtained using Image $\mathrm{J}$ analysis software (National Institutes of Health, Bethesda, MD). 
trophotometrically (Hitachi 911, Roche Diagnostics, Basel, Switzerland) at the Veterinary Diagnostic Laboratory, College of Veterinary Medicine, University of Illinois at Urbana-Champaign. Standard laboratory methods were used to measure the plasma creatinine (picric acid method), urea nitrogen (urease method), and albumin (bromocresol green method) concentrations. Plasma creatinine, urea nitrogen, and albumin concentrations were measured on all available plasma samples from cows with ultrasonographically determined LDLT and LDTT. Plasma was also analyzed for plasma glucose (glucose oxidase method), nonesterified fatty acid (NEFA; acyl-CoA synthetase-acyl-CoA oxidase method), and BHB (BHB dehydrogenase method) concentrations as described (Megahed et al., 2015, 2017, 2018a). We were able to calculate mean plasma glucose concentration values for a subset of 85 animals (23 primiparous, 62 multiparous) and mean plasma BHB concentration values for a subset of 57 animals (13 primiparous, 44 multiparous). Plasma NEFA concentrations were determined on a subset of 32 animals comprising 10 primiparous and 22 multiparous animals. The parity proportions of the latter subset reflected those of the sample population, and animals were selected using a random number generator (Microsoft Excel 2010, Microsoft Corp., Redmond, WA) followed by sorting from lowest to highest within parity groups.

\section{Statistical Analysis}

Data were expressed as least squares means \pm standard error of the means (mixed models analyses) or mean \pm standard deviation (summary of overall production indices), and $P<0.05$ was assigned as statistically significant. Analyses were performed using statistical software programs (PROC UNIVARIATE, PROC MIXED, PROC REG; SAS 9.4, SAS Institute Inc., Cary, NC; MedCalc Statistical Software version 18.6, MedCalc Software bvba, Ostend, Belgium). For statistical analysis, the day of blood sampling, BCS, and ultrasonographic measurement were categorized as antepartum d 3 (first value recorded between 4 to $2 \mathrm{~d}$ antepartum) and postpartum d 7, 14, 21, or 28 based on the nearest weekly sample period. For postpartum time assignment, values obtained on postpartum d 4 through 11 were categorized as d 7, values obtained on postpartum d 12 through 16 were categorized as d 14, values obtained on postpartum d 17 through 23 were categorized as d 21, and values obtained on postpartum d 24 through 35 were categorized as d 28 . If 2 values were obtained during the last 11-d period, then the first collected sample was retained for statistical analysis.
Mean postparturient plasma glucose, NEFA, and BHB concentrations were calculated from blood samples obtained from d 3 to 35 .

The incidence of clinical diseases in primiparous and multiparous cows during the study period was compared using Fisher's exact test. Spearman's rho $\left(\mathbf{r}_{\mathbf{s}}\right)$ was used to characterize associations between selected variables of interest. The change in plasma volume from d -3 to 28 was calculated from the packed cell volume as described (Van Beaumont, 1972).

Mixed models ANOVA was used to detect the main effects of parity (2 levels), time, and the interaction between parity and time on variables of interest. The periparturient period of $\mathrm{d}-3,3,7,14,21$, and 28 was selected for analysis. The day of parturition was excluded from analysis to avoid the transient effects of parturition on plasma biochemical concentrations and because of the presence of placental fluids and preferred recumbency by some cows. Time was included in the model as a repeated variable. Cow nested within parity was included in the model as a random effect whenever the between-subjects variation was determined to be significant. Log transformation was used when necessary to achieve a normal distribution or homogeneous variances. An autoregressive covariance structure was used based on the lowest value for Akaike's information criterion. Whenever the $F$-test was significant, Bonferroni-adjusted $P$-values were used to assess differences between primiparous and multiparous cows at a specific day relative to parturition, between day within a parity group, and between $\mathrm{d}-3$ and subsequent days within a parity group.

Passing-Bablok regression was used to characterize the association between plasma creatinine concentration and muscle thickness using the first available paired value for each animal. Mixed models analysis adjusted for parity with an unstructured covariance matrix, random intercept, and cow nested within parity as the subject was used to characterize the relationship between BCS (dependent variable) and BFT, GMT, LDLT, LDTT, and longissimus dorsi thoracic echogenicity (predictor variables).

To investigate whether indices of fat reserves before parturition influenced postparturient muscle mobilization and milk production indices, the BFT and BCS before parturition were separately ranked for primiparous and multiparous cows and the top quartile and bottom quartile were identified. Mixed models ANOVA was used to detect the main effects of parity (2 levels), quartile (2 levels, first and fourth quartile), and the interaction between parity and quartile on selected indices. 
Table 2. Incidence of selected clinical diseases during the first $28 \mathrm{~d}$ of lactation in 106 periparturient Holstein cows

\begin{tabular}{lcccccc}
\hline & \multicolumn{2}{c}{ Primiparous $(\mathrm{n}=34)$} & & \multicolumn{2}{c}{ Multiparous $(\mathrm{n}=72)$} & \\
\cline { 2 - 3 } Health problem & \multirow{2}{*}{ No. } & Incidence $(\%)$ & & \multirow{2}{*}{ No. } & Incidence (\%) & \multirow{2}{*}{$P$-value } \\
\hline Mastitis & 9 & 26.5 & & 25 & 34.7 & 0.40 \\
Lameness & 9 & 26.5 & & 16 & 22.2 & 0.63 \\
Metritis & 9 & 26.5 & & 8 & 11.1 & 0.044 \\
Retained placenta & 4 & 11.8 & & 8 & 11.1 & 0.75 \\
Ketosis & 3 & 8.8 & & 9 & 12.5 & 1.00 \\
Displaced abomasum & 3 & 8.8 & & 1 & 1.4 & 0.096 \\
Milk fever & 2 & 5.9 & & 7 & 9.7 & 0.72 \\
\hline
\end{tabular}

\section{RESULTS}

Table 2 summarizes the incidence of different clinical diseases in primiparous and multiparous animals during the first $28 \mathrm{~d}$ of lactation. Metritis was diagnosed more frequently in primiparous cows than in multiparous cows despite similar rates of retained placenta. All cows recovered quickly after treatment and, consequently, all postpartum data were retained for statistical analysis.

Primiparous cows had a 305-d mature-equivalent milk production of $10,155 \pm 1,489 \mathrm{~kg}$, with $407 \pm 80$ $\mathrm{kg}$ of fat $(4.0 \pm 0.6 \%)$ and $319 \pm 49 \mathrm{~kg}$ of protein $(3.2$ $\pm 0.3 \%)$. Their cumulative mean milk production to 28 DIM was $663 \pm 132 \mathrm{~kg}$, and their mean postparturient plasma glucose, NEFA, and BHB concentrations were $3.4 \pm 0.3 \mathrm{mmol} / \mathrm{L}, 210 \pm 86 \mu \mathrm{mol} / \mathrm{L}$, and $0.85 \pm 0.40$ $\mathrm{mmol} / \mathrm{L}$, respectively. Eight (24\%) of the 34 primiparous cows were culled during the lactation at a median of 123 DIM (range: 39-272). Multiparous cows had a 305 -d mature-equivalent milk production of 10,572 \pm $1,629 \mathrm{~kg}$, with $431 \pm 84 \mathrm{~kg}$ of fat $(4.1 \pm 0.6 \%)$ and $329 \pm 49 \mathrm{~kg}$ of protein $(3.1 \pm 0.2 \%)$. Their cumulative mean milk production to 28 DIM was $1,020 \pm 154 \mathrm{~kg}$, and their mean postparturient plasma glucose, NEFA, and BHB concentrations were $3.0 \pm 0.3 \mathrm{mmol} / \mathrm{L}, 367$ $\pm 152 \mu \mathrm{mol} / \mathrm{L}$, and $0.83 \pm 0.28 \mathrm{mmol} / \mathrm{L}$, respectively. Twenty-six $(36 \%)$ of the 72 multiparous cows were culled during the lactation at a median of 165 DIM (range: 63-390).

Table 3 summarizes the main effects of parity, time, and the interaction between parity and time as evaluated by mixed models analysis on variables of interest. Mixed models ANOVA evaluating the main effects of parity, BFT or BCS quartile, and the interaction between parity and quartile on selected indices did not identify any significant main effects of BFT or BCS quartile, or the interaction between parity and quartile, on the change in LDTT, longissimus dorsi thoracic echogenicity, or the mean postparturient plasma creatinine, urea nitrogen, total protein, albumin, glucose, NEFA, and BHB concentrations and indices of milk production (cumulative milk production in first $28 \mathrm{~d}$ of lactation and 305-d mature-equivalent milk, fat, and protein yields).

\section{$B C S$}

The BCS of primiparous and multiparous cows was decreased $(P<0.009)$ at $7 \mathrm{~d}$ postpartum and continued to decrease until the end of the study period (Figure

Table 3. Mixed models analysis summarizing the main effects of parity and time and the effect of the interaction between parity and time on variables of interest in 106 periparturient Holstein cows

\begin{tabular}{lcccc}
\hline & & \multicolumn{3}{c}{$P$-value } \\
\cline { 3 - 5 } Variable & $\begin{array}{c}\text { No. of } \\
\text { observations }\end{array}$ & Parity & Time & Parity $\times$ time \\
\hline Plasma creatinine (mg/dL) & 222 & 0.29 & $<0.001$ & 0.22 \\
Plasma urea nitrogen (mg/dL) & 222 & $<0.001$ & 0.036 & 0.18 \\
Plasma total protein (g/L) & 556 & 0.014 & $<0.001$ & 0.0023 \\
Plasma albumin (g/L) & 324 & $<0.001$ & $<0.001$ & 0.28 \\
Packed cell volume (vol \%) & 554 & 0.56 & $<0.001$ & 0.19 \\
BCS & 337 & $<0.001$ & $<0.001$ & 0.95 \\
Backfat thickness (mm) & 534 & 0.57 & $<0.001$ & 0.92 \\
Gluteus medius thickness (mm) & 532 & 0.13 & $<0.001$ & 0.0042 \\
Longissimus dorsi loin thickness (mm) & 439 & 0.0044 & $<0.001$ & 0.67 \\
Longissimus dorsi thoracic thickness (mm) & 441 & 0.23 & $<0.001$ & 0.12 \\
Longissimus dorsi thoracic echogenicity (units) & 289 & $<0.001$ & $<0.001$ & 0.51 \\
\hline
\end{tabular}


2A). The overall BCS of primiparous cows was higher $(P<0.001)$ than that of multiparous cows throughout the study period. Least squares means loss in BCS of primiparous and multiparous cows at $28 \mathrm{~d}$ postpartum was 0.59 and 0.68 BCS units, respectively, compared with d 3 antepartum.
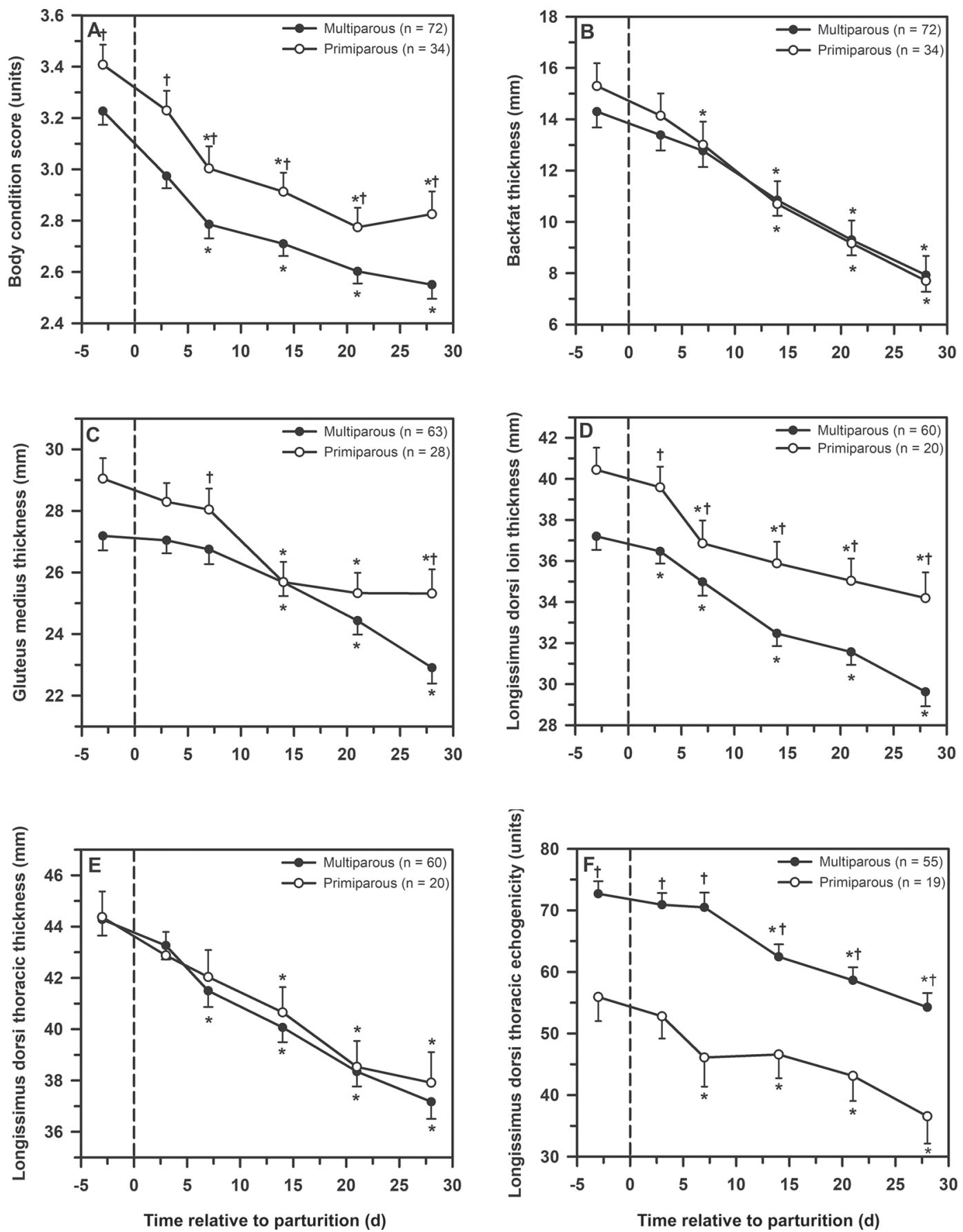

Figure 2. Periparturient changes in (A) BCS, (B) backfat thickness, (C) thickness of the gluteus medius muscle, (D) thickness of the longissimus dorsi muscle in the loin area, (E) thickness of the longissimus dorsi muscle in the thoracic area, and (F) echogenicity of the longissimus dorsi muscle in the thoracic area in up to 106 Holstein cows (primiparous, open circles; multiparous, filled circles). The vertical dashed line indicates parturition. Time is expressed as the mean time that the data were recorded for each interval. Data are presented as LSM \pm SE. $*$ Significantly different from d 3 antepartum $(P$-value $<0.05$, Bonferroni adjusted). †Significantly different between groups at the same time $(P$-value $<0.05)$. 


\section{BFT}

The BFT was significantly decreased in primiparous and multiparous cows from 7 and $14 \mathrm{~d}$ postpartum, respectively, until the end of the study period, with no difference between primiparous and multiparous cows (Figure 2B). Marked reductions in the least squares means BFT of primiparous and multiparous cows of $7.6 \mathrm{~mm}(50 \%)$ and $6.4 \mathrm{~mm}(45 \%)$, respectively, were evident at $28 \mathrm{~d}$ postpartum compared with d 3 antepartum.

\section{Muscle Thickness}

The GMT was decreased at $14 \mathrm{~d}$ postpartum $(P<$ 0.004 ) and continued to decrease until the end of the study period with no overall difference between primiparous and multiparous cows except at $\mathrm{d} 7$ and 28 of lactation (Figure 2C). The least squares means GMT of primiparous and multiparous cows at $28 \mathrm{~d}$ postpartum decreased by $3.8 \mathrm{~mm}(13 \%)$ and $4.3 \mathrm{~mm}(16 \%)$, respectively, compared with d 3 antepartum.

The LDLT was decreased $(P<0.02)$ in primiparous and multiparous cows at 7 and $3 \mathrm{~d}$ postpartum, respectively, and continued to decrease until the end of the study period (Figure 2D). The LDLT of multiparous cows was lower than that of primiparous cows throughout the study period. The least squares means LDLT of primiparous and multiparous cows at $28 \mathrm{~d}$ postpartum was decreased by $6.2 \mathrm{~mm}(15 \%)$ and $7.6 \mathrm{~mm}$ (20\%), respectively, compared with d 3 antepartum.

The LDTT of primiparous and multiparous cows was decreased $(P<0.001)$ at 14 and $7 \mathrm{~d}$ postpartum, respectively, and continued to decrease until the end of the study period, with no overall difference between primiparous and multiparous cows (Figure 2E). The loss in least squares means LDTT of primiparous and multiparous cows at d 28 postpartum was $6.5 \mathrm{~mm}$ (15\%) and $7.1 \mathrm{~mm}(16 \%)$, respectively, compared with d 3 antepartum.

\section{Muscle Echogenicity}

Echogenicity was consistently higher for multiparous cows than for primiparous cows. Echogenicity was decreased $(P<0.01)$ by d 14 of lactation for the longissimus dorsi thoracic muscle compared with d 3 antepartum (Figure 2F). No difference in the echogenicity of the gluteus medius and longissimus dorsi loin muscles was observed between multiparous and primiparous cows; these data were not shown because of the presence of parity-associated differences in BFT, GMT, and LDLT (Figure 2) that could confound muscle echogenicity measurements. The least squares means decrease in echogenicity of the longissimus dorsi thoracic muscle for primiparous and multiparous cows at 28 d postpartum was similar at $19(35 \%)$ and $19(53 \%)$ units, respectively, compared with d 3 antepartum. Longissimus dorsi thoracic echogenicity was positively associated with BFT $\left(\mathrm{r}_{\mathrm{s}}=0.31, P=0.012, \mathrm{n}=64\right)$ for the last data pair available for each cow, indicating that IMF was positively associated with BFT.

\section{Mixed Models Analysis}

Analysis was conducted using a total of 341 observations from 91 cows (primiparous, $\mathrm{n}=28$; multiparous, $\mathrm{n}=63$ ) with up to 5 observations per cow. Mixed models analysis indicated that BFT, GMT, LDLT, and LDTT were significant predictors of BCS, with BCS being influenced by muscle thickness as well as BFT. As expected, based on a scoring system that emphasizes morphologic changes in the dorsal and lateral pelvic regions, the BCS was influenced to a greater extent by changes in GMT (0.024 units/mm change in GMT) than by changes in LDLT ( 0.015 units $/ \mathrm{mm}$ change in LDLT) and LDTT (0.013 units/mm change in LDTT; Table 4). Associations between variables of interest are summarized in Table 5. Longissimus dorsi thoracic echogenicity was not associated with BCS.

\section{Change in Plasma Volume and Plasma Biochemical Analysis}

The least squares means packed cell volume was not influenced by parity or the interaction between parity and time (Table 3) but did decrease over time for all animals from 33.3 at $\mathrm{d}-3$ to 29.7 at $\mathrm{d} 28$. This was equivalent to a calculated increase in plasma volume of $18 \%$.

Plasma creatinine concentrations of primiparous and multiparous cows were decreased $(P<0.03)$ by 7 and 3

Table 4. Mixed models regression analysis characterizing the parityadjusted effect of backfat thickness (BFT), gluteus medius thickness (GMT), longissimus dorsi loin thickness (LDLT), and longissimus dorsi thoracic thickness (LDTT) on BCS ( 1 to 5 in 0.25 -unit increments) in 91 (28 primiparous, 63 multiparous) periparturient Holstein cows from d 3 antepartum to 28 d postpartum ${ }^{1}$

\begin{tabular}{lllll}
\hline Coefficient & $\begin{array}{c}\text { Estimated } \\
\text { value }\end{array}$ & SE & $95 \%$ CI & $P$-value \\
\hline Intercept & 0.99 & 0.16 & $0.67-1.31$ & $<0.001$ \\
BFT (mm) & 0.024 & 0.004 & $0.016-0.033$ & $<0.001$ \\
GMT (mm) & 0.020 & 0.005 & $0.009-0.030$ & $<0.001$ \\
LDLT (mm) & 0.015 & 0.004 & $0.007-0.023$ & $<0.001$ \\
LDTT (mm) & 0.013 & 0.005 & $0.004-0.022$ & 0.0038 \\
\hline
\end{tabular}

${ }^{1}$ Analysis was conducted using a total of 341 observations with up to 5 observations per cow. The $P$-value was $<0.001$ for the overall model. 
d postpartum, respectively, and continued to decrease until the end of the study period (Figure 3A). Least squares means plasma creatinine concentration of primiparous and multiparous cows at $28 \mathrm{~d}$ postpartum decreased by 26 and $27 \%$, respectively, compared with antepartum d 3. Plasma urea nitrogen concentration of primiparous and multiparous cows remained unchanged over the study period. However, plasma urea nitrogen concentration was higher $(P<0.004)$ in multiparous cows on antepartum d 3 and postpartum d 14 and 21 (Figure 3B).

Plasma TP concentration of primiparous and multiparous cows was increased $(P<0.02)$ at $7 \mathrm{~d}$ postpartum and continued to remain increased until the end of the study period compared with d 3 antepartum (Figure 3C). Plasma albumin concentration of primiparous cows was decreased $(P<0.02)$ at 7 and $14 \mathrm{~d}$ postpartum, and that of multiparous cows decreased $(P<0.02)$ at 14 d postpartum, compared with d 3 antepartum (Figure 3D). Plasma albumin concentration was lower $(P<$ $0.001)$ in primiparous cows than multiparous cows on postpartum d 7,14 , and 28 .

Mean postparturient plasma glucose concentration was negatively associated with parity, late-gestation BW, and cumulative 28-d milk production (Table 5). Mean postparturient plasma NEFA concentration was negatively associated with parity, late-gestation BW, cumulative 28-d milk production, 305-d milk and fat production, and mean postparturient glucose concentration. Mean postparturient plasma BHB concentration was positively associated with parity, late-gestation BW, and 305-d milk and fat production and negatively associated with mean postparturient glucose concentration.

\section{Passing-Bablok Regression Analysis}

The results of Passing-Bablok regression analysis characterizing the association between plasma creatinine concentration and muscle thickness are presented in Table 6 . The results indicated that plasma creatinine concentration was weakly ( $\left.\mathrm{r}_{\mathrm{s}}: 0.31-0.39\right)$ associated with GMT, LDLT, and LDTT (Figure 4).

\section{DISCUSSION}

The first major finding of this study was that ultrasound measurement of LDLT and LDTT provides information about the extent of skeletal muscle mobilization during early lactation in dairy cows. The second major finding was that changes in plasma creatinine concentration provide some insight into the rate of skeletal muscle mobilization in periparturient, healthy, euhydrated dairy cows with normal renal function. We 

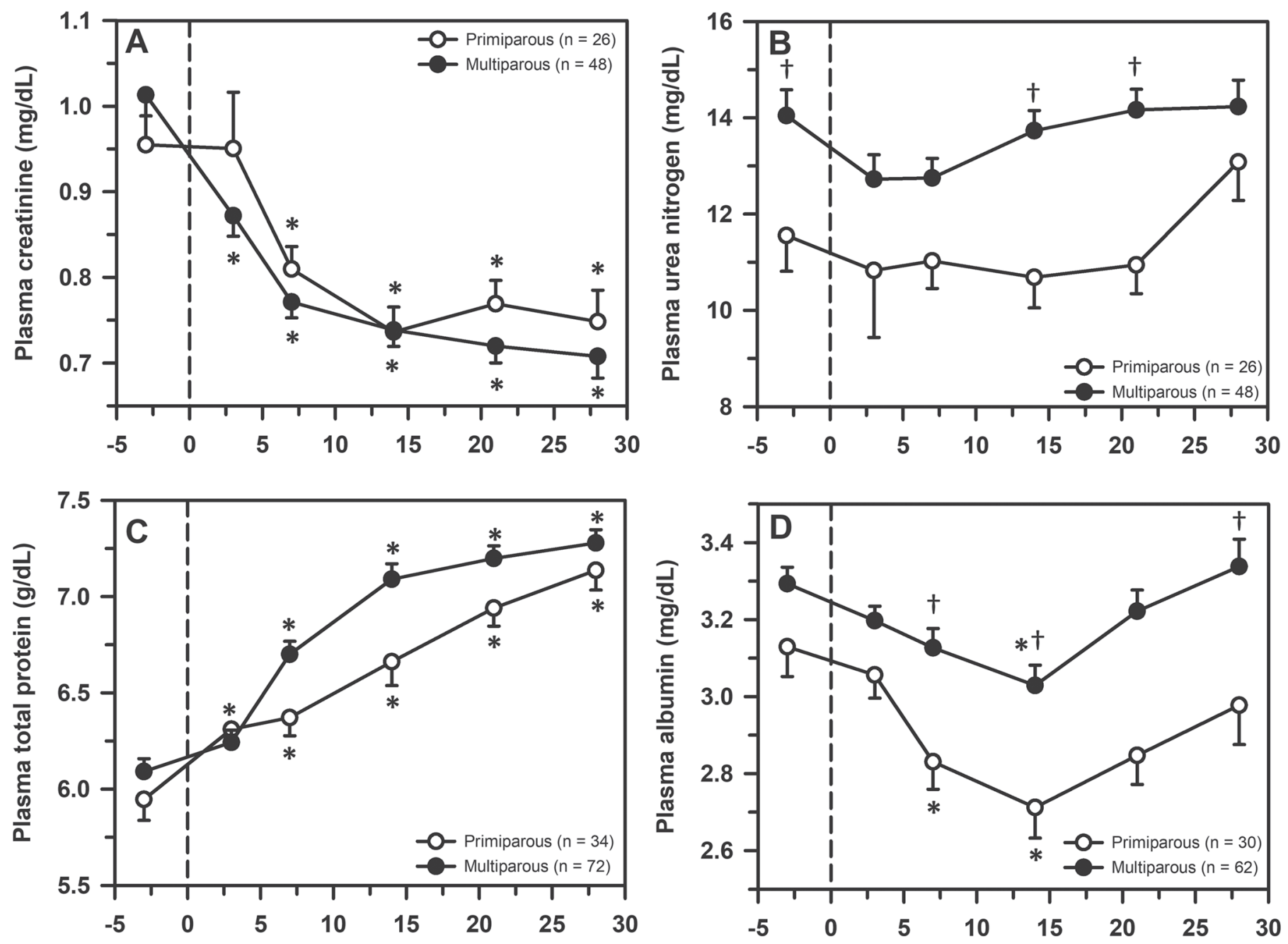

Time relative to parturition (d)

Time relative to parturition $(d)$

Figure 3. Periparturient changes in the (A) plasma creatinine, (B) urea nitrogen, (C) total protein, and (D) albumin concentrations in up to 106 Holstein cows (multiparous, filled circles; primiparous, open circles). The vertical dashed line indicates parturition. Time is expressed as the mean time that the data were recorded for each interval. Data are presented as LSM \pm SE. *Significantly different from d 3 antepartum $(P$-value $<0.05$, Bonferroni adjusted $)$. †Significantly different between groups at the same time $(P$-value $<0.05)$.

Table 6. Results of Passing-Bablok regression analysis characterizing the association between plasma creatinine concentration and gluteus medius thickness (GMT), longissimus dorsi loin thickness (LDLT), and longissimus dorsi thoracic thickness (LDTT) ${ }^{1}$

\begin{tabular}{lcccc}
\hline Item & $\mathrm{n}$ & $\mathrm{r}_{\mathrm{s}}{ }^{2}$ & $P$-value & $\begin{array}{c}\text { Linear regression } \\
\text { equation }^{3}\end{array}$ \\
\hline GMT $(\mathrm{mm})$ & 94 & 0.31 & 0.0024 & $0.43+0.0137 \times$ GMT \\
LDLT $(\mathrm{mm})$ & 82 & 0.39 & $<0.001$ & $0.32+0.0137 \times \mathrm{LDLT}$ \\
LDTT $(\mathrm{mm})$ & 83 & 0.32 & 0.0029 & $0.24+0.0133 \times$ LDTT \\
\hline
\end{tabular}

${ }^{1}$ Analysis was conducted using the first available data pair after parturition for up to 94 postparturient Holstein cows (29 primiparous, 65 multiparous) from d 3 to 28 postpartum.

${ }^{2}$ Spearman's rho.

${ }^{3}$ Plasma creatinine concentration $(\mathrm{mg} / \mathrm{dL})=\mathrm{a}+\mathrm{bx}$. determined that longissimus dorsi thoracic echogenicity was positively associated with BFT and that decreased skeletal muscle thickness was partly due to decreased IMF content, and we confirmed previous findings that BCS in dairy cows was influenced by both BFT and skeletal muscle thickness (Reid et al., 1986; Sloniewski et al., 2004; Jaurena et al., 2005).

The optimal BCS of Holstein-Friesian dairy cows at calving ranges from 3.0 to 3.5 (Roche et al., 2009), and the target BCS loss by 30 DIM should not exceed 0.5 BCS units (Ferguson et al., 1994). In this study, BCS at parturition was within the optimal range, but the least squares means loss in BCS by $28 \mathrm{~d}$ postpartum of 0.59 

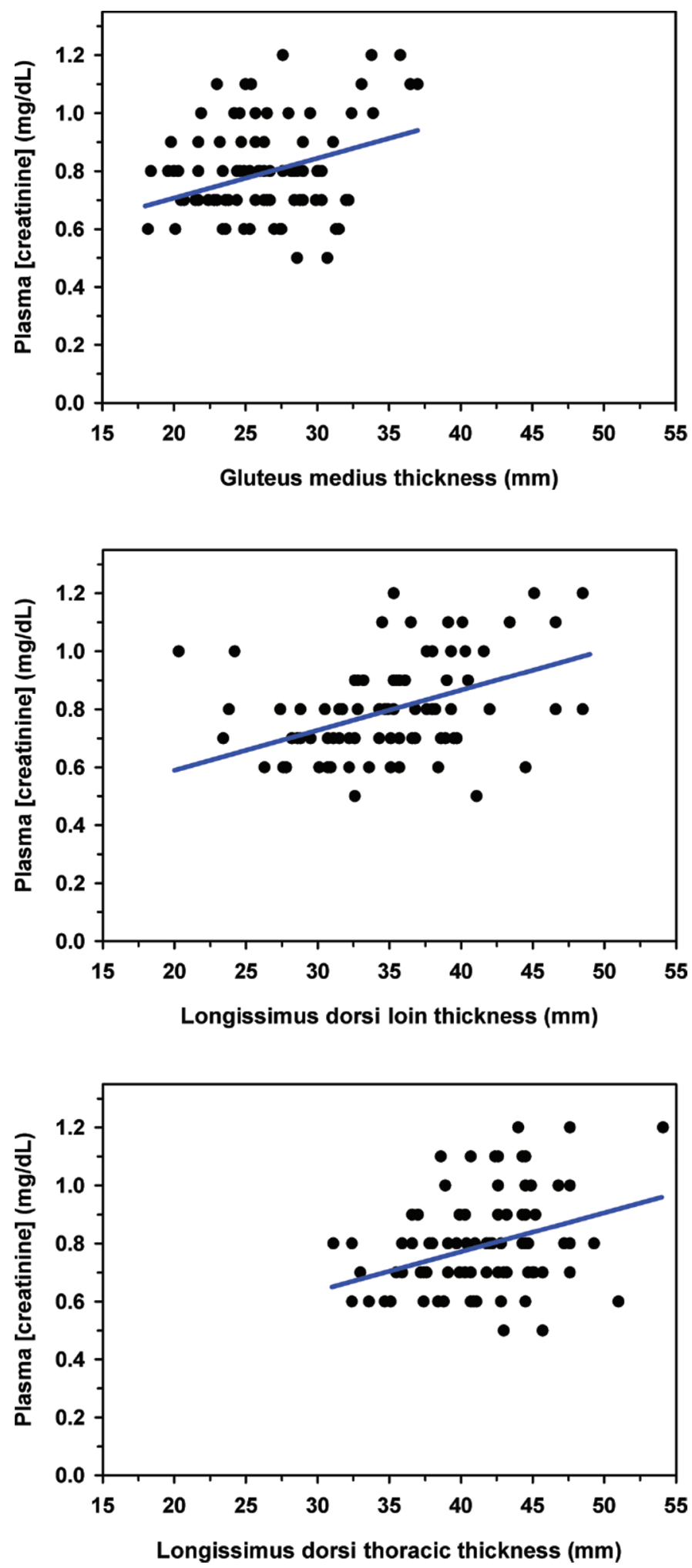

Figure 4. Scatterplot of the linear relationship between plasma creatinine concentration and gluteus muscle thickness (primiparous, $\mathrm{n}$ $=28$; multiparous, $\mathrm{n}=63$ ), longissimus dorsi loin thickness (primiparous, $\mathrm{n}=20$; multiparous, $\mathrm{n}=60$ ), and longissimus dorsi thoracic thickness (primiparous, $\mathrm{n}=20$; multiparous, $\mathrm{n}=60$ ) in Holstein cows. The solid line indicates the Passing-Bablok regression line. and 0.68 in primiparous and multiparous cows, respectively, slightly exceeded the target BCS loss. We found that BCS was linearly related to BFT, GMT, LDLT, and LDTT; however, it needs to be recognized that IMF provides a portion of the contribution of muscle thickness to BCS. A positive curvilinear association has been reported between BCS and LDLT in dairy cows (Otto et al., 1991; Moorby et al., 2002; Jaurena et al., 2005). Our mixed models analysis produced an intercept value that was not significantly different from 1 , which was appropriate for a scoring system that ranges from 1 to 5 and is dependent on both BFT and muscle thickness. Mixed models analysis also indicated that BCS decreased by 0.024 units per millimeter decrease in BFT and by 0.048 units per millimeter decrease in the sum of GMT, LDLT, and LDTT. For comparison, Jaurena et al. (2005) determined that BCS, measured on a 0 -to- 5 scale, decreased by 0.027 units per millimeter decrease in BFT and by 0.050 units per millimeter decrease in LDLT. The agreement between the 2 studies suggests that these relationships might be applicable to changes in BCS based on a 1-to-5 or 0-to-5 scale for Holstein cows in other geographic locations.

The loss in BFT over the periparturient period in this study was similar to (Schäff et al., 2013) or greater than (Bruckmaier et al., 1998a; van der Drift et al., 2012 ) that reported elsewhere. Interestingly, the results of our study did not reveal a significant effect of parity on the rate of backfat mobilization; this finding contrasted with those of other studies that indicated that multiparous cows had a higher rate of backfat mobilization than primiparous cows (Schröder and Staufenbiel, 2006; Wathes et al., 2007). We speculate that one reason for the difference may be that the heifers in this study were well grown at parturition, based on withers height (Hiew et al., 2016), and therefore needed less energy for growth. Additionally, primiparous cows were in higher BCS at parturition than multiparous cows and therefore potentially had more fat to mobilize.

Monitoring GMT using ultrasonography is faster and less stressful to the animal than measuring LDLT and LDTT because the same site can also be used for measuring BFT (Schröder and Staufenbiel, 2006). However, variability in weight bearing by the hind limbs affects the measured GMT value (Brethour, 1992), and the $\mathrm{r}_{\mathrm{s}}$ value for the relationship between GMT and plasma creatinine concentration in this study was numerically lower than that identified for LDLT and plasma creatinine concentration. Ultrasonographic measurement of LDLT and LDTT provides a more accurate prediction of total muscle mass in beef cows than ultrasonographic measurement of GMT (Waldner et al., 1992; Bruckmaier et al., 1998b; Realini et al., 2001), with ultrasonographic measurement of LDTT (Perkins et al., 
1992; Waldner et al., 1992) or slaughter measurement of the loin eye area (Gresham et al., 1986) providing an accurate estimate of total carcass muscle in most, but not all, studies (Bruckmaier et al., 1998b). Measurement of LDLT appears to be more accurate than LDTT in estimating total carcass muscle because of the improved resolution in measuring muscle thickness in the loin area as there is no interference with overlaying ribs (Bruckmaier et al., 1998b; Jaurena et al., 2005; van der Drift et al., 2012). Taking these findings in conjunction with those of the study reported here, we suggest that either the LDLT or the LDTT should be used to monitor the rate of muscle mobilization during early lactation in Holstein cows.

This appears to be the first study to quantify muscle echogenicity in periparturient dairy cows through grayscale histogram analysis and thereby provide an estimate of changes in IMF. The observed decrease in longissimus dorsi thoracic echogenicity after parturition confirmed our hypothesis that periparturient decreases in muscle thickness reflect mobilization of both skeletal muscle and IMF. The higher echogenicity in multiparous cows than in primiparous cows was probably due to age-related changes where muscle mass in older cows tends to be replaced by fat and connective tissue due to a decrease in growth hormone release that stimulates muscle development (Young et al., 2015). In addition, fat mobilization from other fat depots in early lactation is usually greater than the cow needs to correct the energy deficit leading to the development of fatty liver and fatty muscle, with postparturient increases in IMF paralleling increases in liver fat percentage (Roberts et al., 1983). The higher value for longissimus dorsi thoracic echogenicity in multiparous cows was not confounded by parity-associated differences in subcutaneous fat and muscle depth (Thijssen et al., 2008; Starke et al., 2010), as BFT and LDTT were similar throughout the study period for multiparous and primiparous cows.

Plasma or serum creatinine concentration is routinely measured to evaluate the adequacy of renal function in both animals and humans as it provides an index of glomerular filtration rate (Wyss and Kaddurah-Daouk, 2000; Braun et al., 2003). Acute dehydration decreases glomerular filtration rate and thereby increases plasma creatinine concentration (Braun et al., 2003). In contrast, skeletal muscle wasting decreases muscle mass and the rate of creatinine production, thereby decreasing plasma creatinine concentration in euhydrated animals. Monitoring changes in plasma creatinine concentration therefore provides a clinically useful indicator of muscle mass (Bruckmaier et al., 1998b) and the rate and magnitude of skeletal muscle mobilization in periparturient euhydrated dairy cows with normal renal function. Our finding that plasma creatinine concentration decreased in early lactation was consistent with the results of other studies in periparturient dairy cows (Bruckmaier et al., 1998a; Aeberhard et al., 2001). Part of this decrease was due to a calculated increase in plasma volume of $18 \%$ from $\mathrm{d}-3$ to +28 relative to parturition; however, the apparent volume of distribution of creatinine is equal to the total body water, and consequently most of the decrease in plasma creatinine concentration is due to decreased muscle mass, with a minor contribution from plasma volume expansion. Although confounded by changes in plasma volume, the change in plasma creatinine concentration provides a simpler and less expensive laboratory test for estimating the rate of skeletal muscle mobilization than monitoring plasma 3-methylhistidine (3-MH) concentration, which has been used in other studies (Kokkonen et al., 2005; van der Drift et al., 2012). The change in plasma $3-\mathrm{MH}$ concentration in early lactation differs from that of plasma creatinine concentration in that plasma $3-\mathrm{MH}$ concentration peaks during the first week postpartum, reflecting the intensity of skeletal muscle metabolism with a smaller contribution from postparturient uterine evolution (Plaizier et al., 2000), whereas the change in plasma creatinine concentration usually indicates a change in total muscle mass (Bell and Bauman, 1997; Doepel et al., 2002; Pires et al., 2013). Plasma 3-MH and creatinine concentrations may provide complementary measures of muscle mobilization, and the ratio of plasma $3-\mathrm{MH}$ to creatinine concentration has been proposed to normalize the rate of muscle mobilization to the muscle mass (Pires et al., 2013). Interestingly, our results failed to identify a difference in plasma creatinine concentration between primiparous and multiparous cows despite the presence of a lower GMT and LDLT in multiparous cows compared with primiparous cows. This finding is most likely because the multiparous cows in our study were longer, wider, and heavier than primiparous cows but of similar height (Hiew et al., 2016). Because we measured muscle only in the vertical plane, we were not able to detect changes in muscle dimensions in the other 2 planes.

Similar to the results of a previous study (Wathes et al., 2007), we found that plasma urea nitrogen concentration was consistently lower in primiparous cows than in multiparous cows in the periparturient period. This most likely reflects a significantly lower daily protein intake due to a lower DMI (Megahed et al., 2018b) and greater need for ingested protein in primiparous cows for growth. Alternatively, the result could reflect a greater decrease in ureagenesis by the liver or lower 
DMI as a percentage of BW in primiparous cows (Santos et al., 2001).

The decreased plasma albumin concentration in primiparous cows identified in this study during early lactation could have resulted from impaired liver function secondary to hepatic lipidosis, plasma volume expansion, metabolism of albumin for energy, or increased loss of albumin from the intravascular compartment (Little, 1974; Rowlands and Manston, 1983; Bertoni et al., 2008). In this study, the decreased plasma albumin concentration in primiparous cows was probably due, in part, to the higher incidence of metritis $(27 \%)$ in this group compared with multiparous cows (11\%). Acute inflammatory disorders downregulate albumin synthesis in the liver, and extensive destruction of myometrial tissue in cows with metritis causes a direct loss of albumin into the uterine lumen (Bertoni et al., 2008; Burke et al., 2010). Interestingly, when cows with a diagnosis of metritis $(\mathrm{n}=17)$ were excluded from repeated measures ANOVA, similar significant differences in plasma albumin concentration within a group over time and between groups at the same time were observed (data not shown). This finding suggests the presence of subclinical endometritis (Burke et al., 2010) or other concurrent pathophysiological mechanisms for hypoalbuminemia, such as hepatic lipidosis (Rowlands and Manston, 1983). Hypoalbuminemia does not appear to be due to high milk production (Aeberhard et al., 2001).

We did not identify a difference in mean postpartum plasma NEFA concentrations between the top and bottom precalving BCS quartiles after adjustment for parity. This result was unexpected in that cows with a higher BCS at parturition would be expected to have higher plasma NEFA concentrations during early lactation than low-BCS cows. We attribute our result to the combined effects of the absence of markedly overconditioned multiparous cows in the herd, the relatively small $(\mathrm{n}=32)$ number of cows that had mean postpartum plasma NEFA concentrations determined, and the low mean postpartum values for primiparous $(210 \mu \mathrm{mol} / \mathrm{L})$ and multiparous $(367 \mu \mathrm{mol} / \mathrm{L})$ cows. Additional studies in this area will be challenging to complete unless the cost of plasma NEFA testing is decreased.

The major limitation of the study reported here was that it was conducted on one farm. Additional studies are therefore indicated to confirm the external validity of the results; however, cow numbers in the study were greater than in most cited studies. An additional limitation of the study was the use of mean grayscale analysis as an index of IMF because echogenicity units cannot be directly quantified in terms of IMF percentage (Young et al., 2015). Development of a validated automated method that directly calculates IMF per- centage in the longissimus dorsi muscle of dairy cows, such as a thresholding segmentation method, would be beneficial. Finally, North American clinical pathology laboratories have historically reported plasma creatinine concentration to 1 decimal place when expressed in units of milligrams per deciliter. For comparison, European laboratories express plasma creatinine concentration to 3 decimal places in units of micromoles per liter $(1 \mathrm{mg} / \mathrm{dL}=0.011 \mu \mathrm{mol} / \mathrm{L})$. Reporting plasma creatinine concentration in milligrams per deciliter to 2 decimal places would improve the resolution of this analyte as an index of muscle mass.

\section{CONCLUSIONS}

Ultrasonographic measurement of the depth of the longissimus dorsi muscle in the loin or thoracic regions has the potential to provide a useful on-farm method for monitoring the rate of skeletal muscle mobilization during early lactation in Holstein-Friesian cows. Ultrasonographic measurement of muscle thickness and echogenicity complements ultrasonographic measurement of BFT and visual assessment of BCS in the evaluation of energy reserve mobilization in early lactation. Changes in plasma creatinine concentration may provide a complementary method for monitoring the rate of skeletal muscle mobilization in Holstein-Friesian cows, particularly when the concentration is measured in units of milligrams per deciliter and reported to 2 decimal places.

\section{ACKNOWLEDGMENTS}

The authors thank the staff at the Purdue Dairy Research and Education Center (West Lafayette, IN) and the staff at the Clinical Pathology Laboratory, College of Veterinary Medicine, at the University of Illinois at Urbana-Champaign.

\section{REFERENCES}

Aass, L., C. G. Fristedt, and J. D. Gresham. 2009. Ultrasound prediction of intramuscular fat content in lean cattle. Livest. Sci. 125:177-186.

Aeberhard, K., R. M. Bruckmaier, and J. W. Blum. 2001. Metabolic, enzymatic and endocrine status in high-yielding dairy cows - Part 2. J. Vet. Med. A Physiol. Pathol. Clin. Med. 48:111-127.

Bell, A. W., and D. E. Bauman. 1997. Adaptations of glucose metabolism during pregnancy and lactation. J. Mammary Gland Biol. Neoplasia 2:265-278.

Bertoni, G., E. Trevisi, X. Han, and M. Bionaz. 2008. Effects of inflammatory conditions on liver activity in puerperium period and consequences for performance in dairy cows. J. Dairy Sci. 91:3300 3310.

Braun, J. P., H. P. Lefebvre, and A. D. J. Watson. 2003. Creatinine in the dog: A review. Vet. Clin. Pathol. 32:162-179.

Brethour, J. R. 1992. The repeatability and accuracy of ultrasound in measuring backfat of cattle. J. Anim. Sci. 70:1039-1044. 
Bruckmaier, R. M., L. Gregoretti, F. Jans, D. Faissler, and J. W. Blum. 1998a. Longissimus dorsi muscle diameter, backfat thickness, body condition score and skinfold values related to metabolic and endocrine traits in lactating dairy cows fed crystalline fat or free fatty acid. Zentralbl. Veterinarmed. A 45:397-410.

Bruckmaier, R. M., E. Lehmannd, D. Hugi, H. M. Hammon, and J. W. Blum. 1998b. Ultrasound longissimus dorsi and backfat accretion associated with metabolic and endocrine changes during fattening of bulls and steers. Livest. Prod. Sci. 53:123-134.

Burke, C. R., S. Meier, S. McDougall, C. Compton, M. Mitchell, and J. R. Roche. 2010. Relationships between endometritis and metabolic state during the transition period in pasture-grazed dairy cows. J. Dairy Sci. 93:5363-5373.

Doepel, L., H. Lapierre, and J. J. Kennelly. 2002. Peripartum performance and metabolism of dairy cows in response to prepartum energy and protein intake. J. Dairy Sci. 85:2315-2334.

Domecq, J. J., A. L. Skidmore, J. W. Lloyd, and J. B. Kaneene. 1995. Validation of body condition scores with ultrasound measurements of subcutaneous fat of dairy cows. J. Dairy Sci. 78:2308-2313.

Drackley, J. K. 1999. Biology of dairy cows during the transition period: The final frontier? J. Dairy Sci. 82:2259-2273.

Ferguson, J. D., D. T. Galligan, and N. Thrnsen. 1994. Principal descriptors of body condition score in Holstein cows. J. Dairy Sci. 77:2695-2703.

Gillis, W. A., T. D. Burgess, W. R. Usborne, H. Greiger, and S. Talbot. 1973. A comparison of two ultrasonic techniques for the measurement of fat thickness and rib eye position in cattle. Can. J. Anim. Sci. 53:13-19.

Gresham, J. D., J. W. Holloway, W. T. Butts, and J. R. McCurley. 1986. Prediction of mature cow carcass composition from live animal measurements. J. Anim. Sci. 63:1041-1048.

Grummer, R. R., D. G. Mashek, and A. Hayirli. 2004. Dry matter intake and energy balance in the transition period. Vet. Clin. North Am. Food Anim. Pract. 20:447-470.

Health, E. A. 1996. Body condition scoring. Bulletin AI 8478 (Rev 9/96). Elanco Animal Health, Indianapolis, IN.

Heinrichs, A. J., G. W. Rogers, and J. B. Cooper. 1992. Predicting body weight and wither height in Holstein heifers using body measurements. J. Dairy Sci. 75:3576-3581.

Herdt, T. H. 2000. Ruminant adaptation to negative energy balance Influences on the etiology of ketosis and fatty liver. Vet. Clin. North Am. Food Anim. Pract. 16:215-230.

Hiew, M. W. H., A. A. Megahed, J. R. Townsend, W. L. Singleton, and P. D. Constable. 2016. Clinical utility of calf front hoof circumference and maternal intrapelvic area in predicting dystocia in 103 late gestation Holstein-Friesian heifers and cows. Theriogenology 85:384-395.

Jaurena, G., and J. M. Moorby. 2017. Lactation and body composition responses to fat and protein supplies during the dry period in under-conditioned dairy cows. J. Dairy Sci. 100:1107-1121.

Jaurena, G., J. M. Moorby, W. J. Fisher, and R. Cantet. 2005. Association of body weight, loin longissimus dorsi and backfat with body condition score in dry and lactating Holstein dairy cows. J. Anim. Sci. 80:219-223.

Kokkonen, T., J. Taponen, T. Anttila, L. Syrjälä-Qvist, C. Delavaud, Y. Chilliard, M. Tuori, and A. T. Tesfa. 2005. Effect of body fatness and glucogenic supplement on lipid and protein mobilization and plasma leptin in dairy cows. J. Dairy Sci. 88:1127-1141.

Komaragiri, M. V. S., D. P. Casper, and R. A. Erdman. 1998. Factors affecting body tissue mobilization in early lactation dairy cows. 2 . Effect of dietary fat on mobilization of body fat and protein. J. Dairy Sci. 81:169-175.

Little, W. 1974. An effect of the stage of lactation on the concentration of albumin in the serum of dairy cows. Res. Vet. Sci. 17:193-199.

Megahed, A. A., M. W. Hiew, S. A. El Badawy, and P. D. Constable. 2018b. Plasma calcium concentrations are decreased at least 9 hours before parturition in multiparous Holstein-Friesian cattle in a herd fed an acidogenic diet during late gestation. J. Dairy Sci. 101:1365-1378.

Megahed, A. A., M. W. Hiew, J. R. Townsend, and P. D. Constable. 2017. Characterization of the analytic performance of an electro- chemical point-of-care meter for measuring $\beta$-hydroxybutyrate concentration in blood and plasma from periparturient dairy cattle. Vet. Clin. Pathol. 46:314-325.

Megahed, A. A., M. W. H. Hiew, and P. D. Constable. 2018a. Clinical utility of plasma fructosamine concentration as a hypoglycemic biomarker during early lactation in dairy cattle. J. Vet. Intern. Med. 32:846-852.

Megahed, A. A., M. W. H. Hiew, J. R. Townsend, J. B. Messick, and P. D. Constable. 2015. Evaluation of an electrochemical point-of-care meter for measuring glucose concentration in blood from periparturient dairy cattle. J. Vet. Intern. Med. 29:1718-1727.

Moorby, J. M., R. J. Dewhurst, R. T. Evans, and W. J. Fisher. 2002. Effects of level of concentrate feeding during the second gestation of Holstein-Friesian dairy cows. 2. Nitrogen balance and plasma metabolites. J. Dairy Sci. 85:178-189.

National Research Council. 2001. Nutrient Requirements of Dairy Cattle. 7th rev. ed. Natl. Acad. Press, Washington, DC.

Otto, K. L., J. D. Ferguson, D. G. Fox, and C. J. Sniffen. 1991. Relationship between body condition score and composition of ninth to eleventh rib tissue in Holstein dairy cows. J. Dairy Sci. 74:852-859.

Perkins, T. L., R. D. Green, and K. E. Hamlin. 1992. Evaluation of ultrasonic estimates of carcass fat thickness and longissimus muscle area in beef cattle. J. Anim. Sci. 70:1002-1010.

Pillen, S. 2010. Skeletal muscle ultrasound. Eur. J. Transl. Myol. $1: 145-155$

Pillen, S., R. O. Tak, M. J. Zwarts, M. M. Y. Lammens, K. N. Verrijp, I. M. P. Arts, J. A. van der Laak, P. M. Hoogerbrugge, B. G. M. van Engelen, and A. Verrips. 2009. Skeletal muscle ultrasound: Correlation between fibrous tissue and echo intensity. Ultrasound Med. Biol. 35:443-446.

Pires, J. A. A., C. Delavaud, Y. Faulconnier, D. Pomiès, and Y. Chilliard. 2013. Effects of body condition score at calving on indicators of fat and protein mobilization of periparturient Holstein-Friesian cows. J. Dairy Sci. 96:6423-6439.

Plaizier, J. C., J. P. Walton, A. Martin, T. Duffield, R. Bagg, P. Dick, and B. W. McBride. 2000. Effects of monensin on 3-methylhistidine excretion in transition dairy cows. J. Dairy Sci. 83:2810-2812.

Realini, C. E., R. E. Williams, T. D. Pringle, and J. K. Bertrand. 2001 Gluteus medius and rump fat depths as additional live animal ultrasound measurements for predicting retail product and trimmable fat in beef carcasses. J. Anim. Sci. 79:1378-1385.

Reid, I. M., C. J. Roberts, and G. D. Baird. 1980. The effects of underfeeding during pregnancy and lactation on structure and chemistry of bovine liver and muscle. J. Agric. Sci. 94:239-245.

Reid, I. M. C. J. Roberts, R. J. Treacher, and L. A. Williams. 1986 Effect of body condition at calving on tissue mobilization, development of fatty liver and blood chemistry of dairy cows. Anim. Prod. 43:7-15.

Roberts, C. J., B. A. Turfrey, and A. P. Bland. 1983. Lipid deposition in different fiber types of skeletal muscle of periparturient dairy cows. Vet. Pathol. 20:23-31.

Roche, J. R., N. C. Friggens, J. K. Kay, M. W. Fisher, K. J. Stafford, and D. P. Berry. 2009. Invited review: Body condition score and its association with dairy cow productivity, health, and welfare. J. Dairy Sci. 92:5769-5801.

Rowlands, G. J., and R. Manston. 1983. Decline of serum albumin concentration at calving in dairy cows: Its relationship with age and association with subsequent fertility. Res. Vet. Sci. 34:90-96.

Santos, J. E. P., E. J. DePeters, P. W. Jardon, and J. T. Huber. 2001. Effect of prepartum dietary protein level on performance of primigravid and multiparous Holstein dairy cows. J. Dairy Sci. $84: 213-224$

Schäff, C., S. Börner, S. Hacke, U. Kautzsch, H. Sauerwein, S. K. Spachmann, M. Schweigel-Röntgen, H. M. Hammon, and B. Kuhla. 2013. Increased muscle fatty acid oxidation in dairy cows with intensive body fat mobilization during early lactation. J. Dairy Sci. 96:6449-6460.

Schröder, U. J., and R. Staufenbiel. 2006. Invited review: Methods to determine body fat reserves in the dairy cow with special regard to ultrasonographic measurement of backfat thickness. J. Dairy Sci. 89:1-14. 
Silva, S., M. Patrício, C. Guedes, E. Mena, A. Silva, V. Santos, and A. Jorge. 2010. Assessment of muscle longissimus thoracis and lumborum intramuscular fat by ultrasonography and image analysis. Pages 211-215 in Proc. 6th International Conference on Simulation and Modelling in the Food and Bio Industries, Braganca, Portugal. V. Cadavez and D. Thiel, ed. Eurosis, Ostend, Belgium.

Sloniewski, K., I. L. Mao, J. Jensen, and P. Madsen. 2004. Changes in ultrasound measures of muscle and its genetic variation during lactation in dairy cows. Anim. Sci. 79:365-372.

Starke, A., A. Haudum, G. Weijers, K. Herzog, P. Wohlsein, M. Beyerbach, C. L. De Korte, J. M. Thijssen, and J. Rehage. 2010. Noninvasive detection of hepatic lipidosis in dairy cows with calibrated ultrasonographic image analysis. J. Dairy Sci. 93:2952-2965.

Tamminga, S., P. A. Luteijn, and R. G. M. Meijer. 1997. Changes in composition and energy content of liveweight loss in dairy cows with time after parturition. Livest. Prod. Sci. 52:31-38.

Thijssen, J. M., A. Starke, G. Weijers, A. Haudum, K. Herzog, P. Wohlsein, J. Rehage, and C. L. De Korte. 2008. Computer-aided Bmode ultrasound diagnosis of hepatic steatosis: A feasibility study. IEEE Trans. Ultrason. Ferroelectr. Freq. Control 55:1343-1354.

Van Beaumont, W. 1972. Evaluation of hemoconcentration from hematocrit measurement. J. Appl. Physiol. 32:712-713. van der Drift, S. G. A., M. Housweling, J. T. Schonewille, A. G. M. Tielens, and R. Jorritsma. 2012. Protein and fat mobilization and associations with serum $\beta$-hydroxybutyrate concentrations in dairy cows. J. Dairy Sci. 95:4911-4920.

Waldner, D. N., M. E. Dikeman, R. R. Schalles, W. G. Olson, P. L. Houghton, J. A. Unruh, and L. R. Corah. 1992. Validation of realtime ultrasound technology for predicting fat thickness, longissimus muscle area, and composition of Brangus bulls from 4 months to 2 years of age. J. Anim. Sci. 70:3044-3054

Wathes, D. C., Z. Cheng, N. Bourne, V. J. Taylor, M. P. Coffey, and S. Brotherstone. 2007. Differences between primiparous and multiparous dairy cows in the inter-relationships between metabolic traits, milk yield, and body condition score in the periparturient period. Domest. Anim. Endocrinol. 33:203-225.

Wyss, M., and R. Kaddurah-Daouk. 2000. Creatine and creatinine metabolism. Physiol. Rev. 80:1107-1213.

Young, H., N. T. Jenkins, Q. Zhao, and K. K. McCully. 2015. Measurement of intramuscular fat by muscle echo intensity. Muscle Nerve 52:963-971. 